\title{
Osteoblast-Osteoclast Communication and Bone Homeostasis
}

\author{
Jung-Min Kim ${ }^{1}$, Chujiao Lin ${ }^{1}$, Zheni Stavre ${ }^{1}$, Matthew B. Greenblatt ${ }^{2}$ and \\ Jae-Hyuck Shim 1,3,*iD \\ 1 Division of Rheumatology, Department of Medicine, University of Massachusetts Medical School, Worcester, \\ MA 01605, USA; jungmin.kim@umassmed.edu (J.-M.K.); chujiao.lin@umassmed.edu (C.L.); \\ zheni.stavre@umassmed.edu (Z.S.) \\ 2 Department of Pathology and Laboratory Medicine, Weill Cornell Medical College, New York, NY 10065, \\ USA; mag3003@med.cornell.edu \\ 3 Li Weibo Institute for Rare Diseases Research, University of Massachusetts Medical School, Worcester, \\ MA 01605, USA \\ * Correspondence: jaehyuck.shim@umassmed.edu; Tel.: +1-508-856-6245
}

Received: 25 August 2020; Accepted: 8 September 2020; Published: 10 September 2020

\begin{abstract}
Bone remodeling is tightly regulated by a cross-talk between bone-forming osteoblasts and bone-resorbing osteoclasts. Osteoblasts and osteoclasts communicate with each other to regulate cellular behavior, survival and differentiation through direct cell-to-cell contact or through secretory proteins. A direct interaction between osteoblasts and osteoclasts allows bidirectional transduction of activation signals through EFNB2-EPHB4, FASL-FAS or SEMA3A-NRP1, regulating differentiation and survival of osteoblasts or osteoclasts. Alternatively, osteoblasts produce a range of different secretory molecules, including M-CSF, RANKL/OPG, WNT5A, and WNT16, that promote or suppress osteoclast differentiation and development. Osteoclasts also influence osteoblast formation and differentiation through secretion of soluble factors, including S1P, SEMA4D, CTHRC1 and C3. Here we review the current knowledge regarding membrane bound- and soluble factors governing cross-talk between osteoblasts and osteoclasts.
\end{abstract}

Keywords: bone; osteoblast; osteoclast; bone remodeling

\section{Introduction}

Bone is a dynamic tissue that remodels continuously throughout life, providing mechanical support for stature and locomotion and protecting vital organs such as bone marrow and the brain [1]. Bone also functions as a reservoir for calcium and phosphate. Continuous remodeling is required to preserve both of these critical functions by preventing accumulation of bone damage and maintaining both the mechanical strength of bone and calcium homeostasis [2,3].

Bone remodeling is a process in which old or damaged bone is removed by osteoclasts and replaced with new bone formed by osteoblasts. Osteoclasts, bone-resorbing cells, originate from hematopoietic stem cells (HSCs) [4-8] and degrade bone via secretion of acid and proteolytic enzymes, such as cathepsin K (CTSK), that dissolve collagen and other matrix proteins during bone resorption $[9,10]$. Osteoblasts, bone-forming cells, arise from the commitment of mesenchymal precursors to osteoprogenitor lineages through the sequential action of transcriptional factors and terminally differentiate into osteocytes [11-14]. Osteoblasts produce extracellular proteins, including osteocalcin, alkaline phosphatase and type I collagen, the latter of which makes up over $90 \%$ of bone matrix protein. The extracellular matrix is first secreted as unmineralized osteoid and subsequently mineralized through the accumulation of calcium phosphate in the form of hydroxyapatite [15]. The sequential strategies of osteoclastogenesis and osteoblastogenesis are shown in Figure 1. 


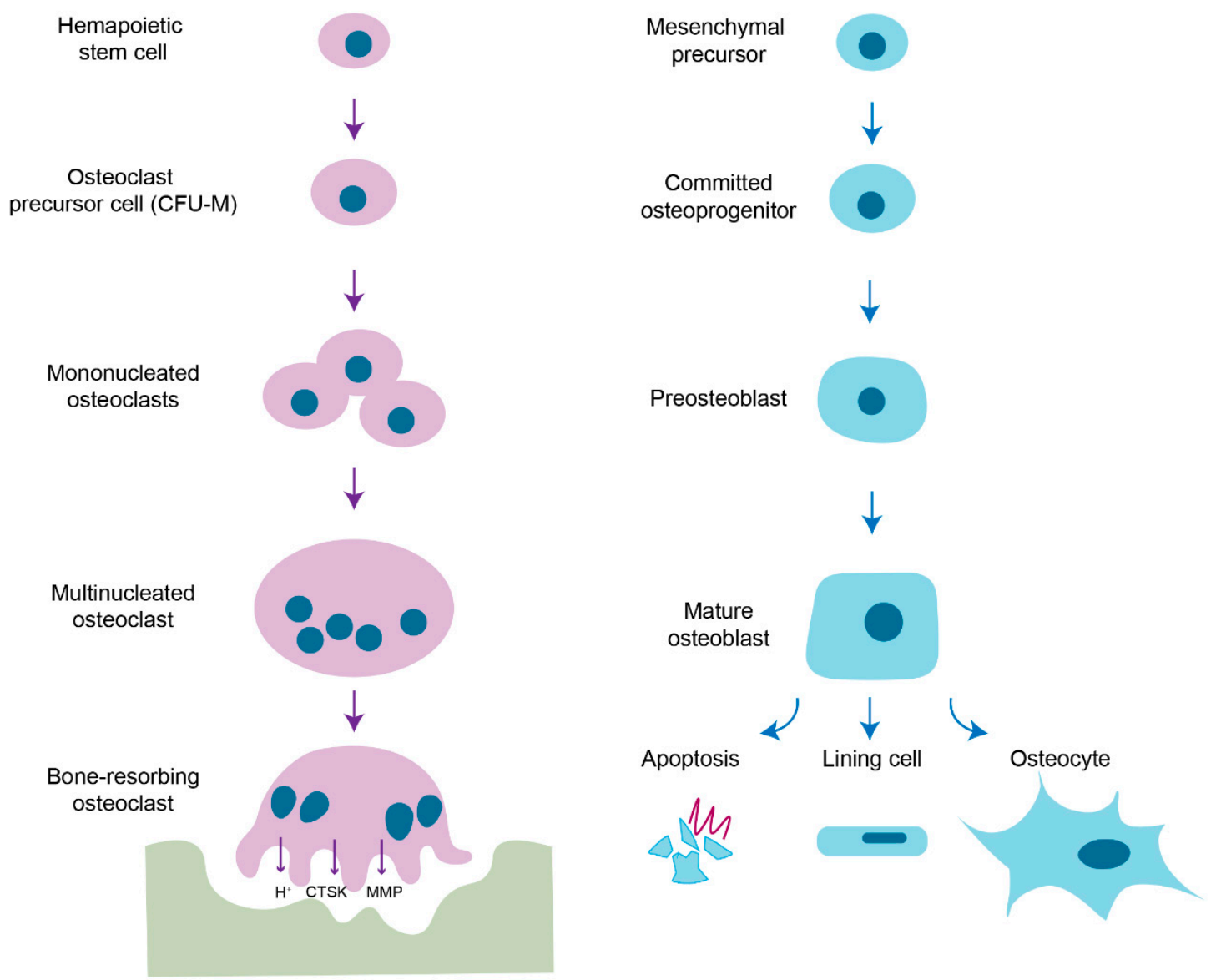

(a) Osteoclastogenesis

(b) Osteoblastogenesis

Figure 1. Strategies of osteoclastogenesis and osteoblastogenesis. (a) Osteoclastogenesis. Osteoclasts are tissue-specific macrophages derived from hematopoietic stem cells. In the presence of M-CSF, hematopoietic stem cells are committed to macrophage colony-forming units (CFU-M), the common precursor cells of macrophages and osteoclasts. When activated by the RANKL-RANK signal, CFU-M is further differentiated into mononucleated osteoclasts and subsequently fuse to become multinucleated osteoclasts. Multinucleated osteoclasts are fully matured upon a cognate interaction with osteoblasts and resorb bone matrix by secreting acids $\left(\mathrm{H}^{+}\right)$, proteases (e.g., CTSK) and matrix metalloproteinases (MMPs) when they have a tight junction between the bone surface and basal membrane of osteoclasts to form a sealed compartment and then osteoclasts. (b) Osteoblastogenesis. Osteoblasts are derived from multipotent mesenchymal precursors and they are committed to osteoprogenitors and further differentiated into osteoblastic lineage through the expression of transcription factors RUNX2 and Osterix. They are continued to differentiation into matrix-producing mature osteoblasts and these cells have different fates: apoptosis, bone lining cells or osteocytes. A subpopulation of mature osteoblasts is surrounded by unmineralized osteoid and further differentiated into osteocytes, terminally differentiated bone cells in mineralized bone.

Bone remodeling is traditionally considered to be composed of four sequential phases [16]: the activation phase when osteoclast progenitors are recruited to damaged bone surface; resorption phase when mature osteoclasts resorb damaged bone; reversal phase when osteoclasts die and osteoblast progenitors are recruited; formation phase when mature osteoblasts produce new bone matrix (osteoid) and this matrix is mineralized $[17,18]$. Almost all new bone formation is observed in areas with previous resorption and in distinct anatomical structures called basic multicellular units (BMUs) [19]. The balance between osteoblast-mediated bone formation and osteoclast-mediated 
bone resorption is tightly regulated without a major alteration in a net bone mass or mechanical strength under homeostatic conditions [2]. However, dysregulation of this balance results in abnormal bone remodeling, resulting in both postmenopausal and secondary forms of osteoporosis, such as diabetes-associated and glucocorticoid-induced osteoporosis [20-22]. In addition to improving understanding of the bone resorption and formation phases, a more detailed study on the reversal phase might be necessary as reversal step dysfunction is associated with pathologic bone loss [23,24].

In this review, we illustrate the key mediators that control the cross-talk between osteoblasts and osteoclasts through cell-cell contact or secretory factors (Figure 2).

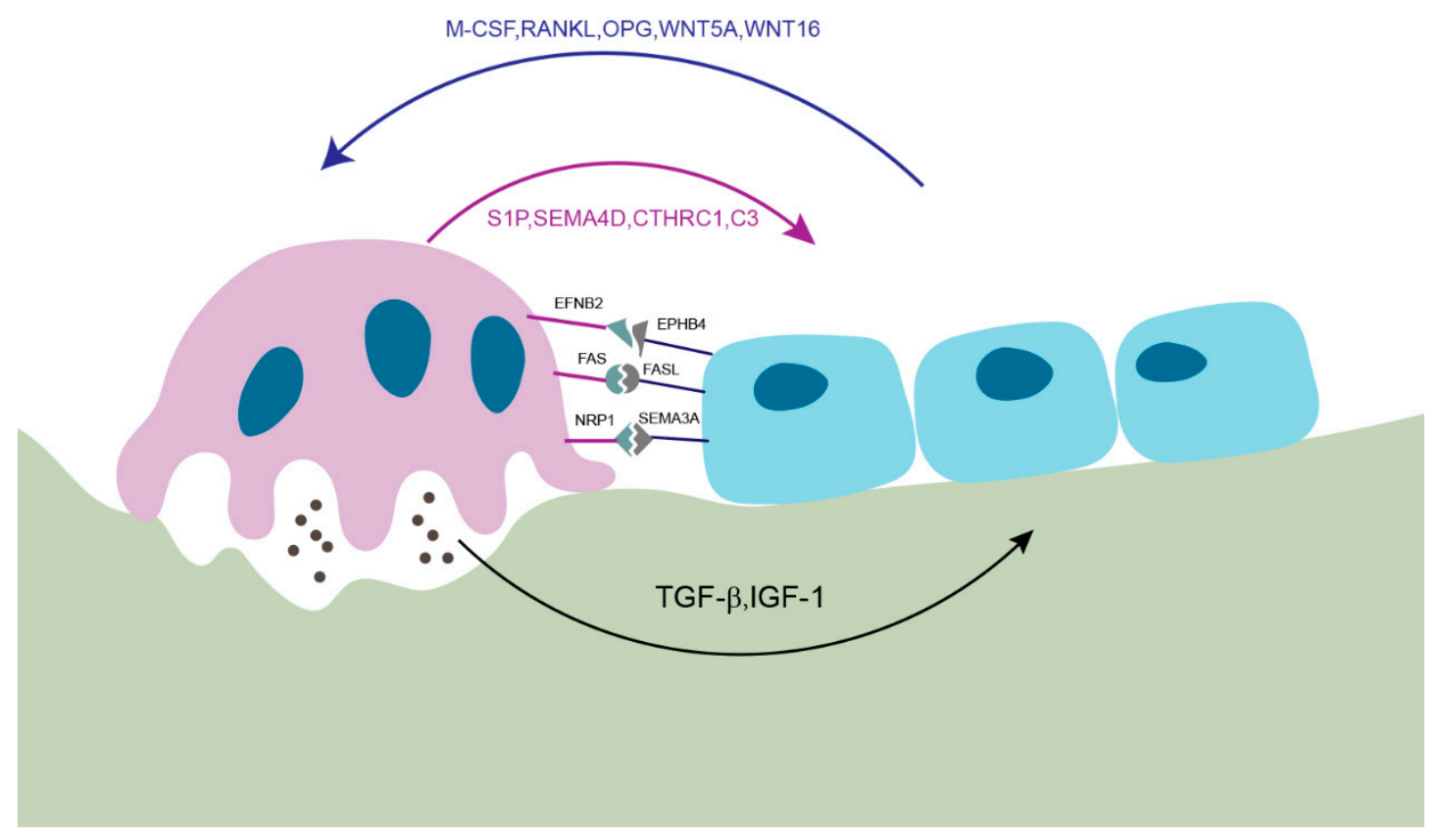

Figure 2. Key mediators of osteoblast-osteoclast interaction. Osteoblast-osteoclast communications are essential for fine-tuning of bone remodeling during bone homeostasis. (1) Osteoblasts and osteoclasts have direct contacts through the interactions between EFNB2-EPHB4, FAS-FASL and NRP1-SEMA3A to regulate cell proliferation, differentiation, and survival. (2) Osteoclast-mediated bone resorption releases TGF- $\beta$ and IGF-1 from bone matrix to induce osteoblast-mediated bone formation. (3) Osteoblasts secrete M-CSF, RANKL, WNT5A that promote osteoclast formation and development and OPG and WNT16 that inhibit osteoclast activity. Conversely, osteoclasts secrete S1P, CTHRC1 and C3 that promote osteoblast differentiation and SEMA4D that suppresses osteoblasts differentiation.

The factors which control osteoblast-osteoclast communication will be reviewed in cellular levels, mainly in genetic mouse models.

\section{Membrane-Bound Mediators of Cell-to-Cell Communication}

\subsection{EFNB2 (Ephrin B2)-EPHB4}

During bone remodeling, osteoblasts and osteoclasts communicate through cell-to-cell direct contact [25]. This interaction can be mediated by Ephrin signaling, which is critical for the bidirectional communication between osteoclasts and osteoblasts [26-28]. Cell-surface molecules Ephrin B (B1 B3) bind to their cognate tyrosine kinase receptors EPHB (B1 B6). The Ephrin B family consists of transmembrane proteins with cytoplasmic domains and its interaction with EPHB-expressing cells mediates bidirectional signal transduction [29]. Ephrin B2 (EFNB2), expressed on the cell surface of osteoclasts, binds to osteoblast surface molecule EPHB4. Reverse signaling (osteoblast to osteoclast) is initiated by EPHB4-mediated activation of EFNB2 and suppresses osteoclast differentiation by 
blocking the osteoclastogenic C-FOS/NFATC1 cascade. In forward signaling (osteoclast to osteoblast), EFNB2-mediated activation of EPHB4 promotes osteoblast differentiation and suppresses apoptosis [30]. Similarly, overexpression of EPHB4 in osteoblasts increases bone mass in a transgenic mouse model [26].

\subsection{FAS Ligand (FASL)-FAS}

FAS (also called as APO-1 or CD95) is a death domain-containing member of the tumor necrosis factor receptor (TNFR) superfamily. FAS ligand (FASL or CD95L) plays a central role in the physiological regulation of apoptosis of FAS-expressing cells, which is associated with various disease processes, such as tumorigenesis and several auto-immune diseases [31,32]. Deficiency of estrogen is closely linked to postmenopausal osteoporosis, and estrogen has been known to induce osteoclast apoptosis [33,34]. In line with the effects of estrogen on osteoclast apoptosis, further study demonstrated that FAS-FASL signaling is involved in estrogen-induced osteoclast apoptosis [35]. Upregulated expression of FASL in osteoblasts by estrogen results in apoptosis of pre-osteoclasts, suggests that a paracrine signal emanating from osteoblasts plays an important role in the protective effects of estrogen in bone. Additional study has demonstrated that conditional knockout of FASL in osteoblasts increases the number and activity of osteoclasts, resulting in reduced bone mass [36]. Similarly, osteoblasts from ovariectomized (estrogen-deficient) mice exhibit a decrease in FASL expression, resulting in reduced osteoclast apoptosis and increased bone resorption.

\subsection{Semaphorin $3 A$ (SEMA3A)-NRP1}

Semaphorins were originally identified as axon guidance factors involved in the development of neuronal system, but they also play a role in various physiological processes including osteoblast-osteoclast interactions [37-39]. Semaphorin 3A (SEMA3A) is the first semaphorin family member identified in vertebrates and ubiquitously expressed in many types of tissue, including brain and bone. While SEMA3A participates in the development of major structures of the nervous system [40], many studies suggest that SEMA3A also plays a key role in both bone modeling and remodeling [40-42]. In particular, sensory neuron-derived SEMA3A is necessary for normal bone formation in vivo [42]. Additionally, SEMA3A, produced by osteoblast lineage cells, functions as a potent osteoprotective factor by synchronously inhibiting bone resorption and promoting bone formation [38]. High levels of SEMA3A were detected in the conditioned media of osteoprotegerin (OPG, anti-osteoclastogenic factor)-deficient osteoblasts, and its binding to neuropilin-1 (NRP1) inhibits RANKL-induced osteoclast differentiation, and promotes osteoblast differentiation through the $\mathrm{WNT} / \beta$-catenin pathway.

\section{Soluble Factors Released from Osteoblasts}

\subsection{Macrophage Colony-Stimulating Factor (M-CSF)}

M-CSF (also called as CSF1) is a hematopoietic growth factor that allows for survival, proliferation, differentiation, and mobility of mononuclear phagocyte lineages, including osteoclasts $[43,44]$. M-CSF, secreted from osteoblasts and bone marrow stromal cells, binds to its cognate receptor C-FMS on the surface of osteoclasts and monocytes/macrophages [45]. Osteopetrotic (op/op) mice where a thymidine insertion in the Csf1 gene resulted in M-CSF deficiency show decreased numbers of macrophages and osteoclasts at a young age. However, these phenotypes disappear during aging. Injection of recombinant M-CSF or production of soluble M-CSF in osteoblasts increases osteoclast numbers and rescues osteopetrotic phenotypes in op/op mice, demonstrating that M-CSF is crucial for osteoclast formation at least in young mice, but does not exclude the existence of M-CSF-independent compensatory mechanisms. 


\subsection{Receptor Activator of NF- $\kappa B$ (Nuclear Factor-Kappa B) Ligand (RANKL)}

RANKL is also called osteoclast differentiation factor (ODF), TNF ligand superfamily member 11 (TNFSF11), TNF-related activation-induced cytokine (TRANCE), and OPG ligand (OPGL) [46,47]. RANKL is highly expressed in osteoblasts, osteocytes, activated T lymphocytes, and lymph nodes [48-50]. RANKL binds to its cognate receptor, receptor activator of NF-KB (RANK) on the surface of osteoclasts and osteoclast precursors, leading to osteoclast differentiation, fusion, and activation [6,51]. Mice deficient in Tnfrsf11a (RANK) or Tnfsf11 (RANKL) are phenocopies of one another, indicating the essential role of this RANKL/RANK signaling axis in bone remodeling [48,51]. Deletion of RANKL in mice results in severe osteopetrosis due to absence of osteoclasts, whereas overexpression of soluble RANKL leads to severe osteoporosis [48,52]. Accordingly, blocking RANKL signaling has been proposed as a promising therapeutic target for osteoporotic bone loss and related skeletal disorders.

\subsection{Osteoprotegerin (OPG)}

OPG is also known as osteoclastogenesis inhibitory factor (OCIF) and TNF receptor superfamily member 11B (TNFRSF11B) [47,53,54]. OPG was identified as a secreted glycoprotein synthesized by many types of cells, including osteoblasts, lung- or liver-residing cells, and B lymphocytes in the bone marrow [53-55]. Overexpression of OPG results in profound osteopetrosis due to inhibition of osteoclast formation, whereas Tnfrsf $11 b$ (OPG) — deficient mice exhibit rapid postnatal bone loss and severe bone porosity due to an increased osteoclast development $[53,56]$. OPG is considered to function as a decoy receptor binding to RANKL, negatively regulating osteoclast differentiation and activation by blocking the RANKL-RANK interaction [6,57].

\subsection{WNT5A}

The WNT pathway is crucial for the maintenance of bone homeostasis by regulating osteoblastogenesis and osteoclastogenesis through both $\beta$-catenin-dependent (canonical) and -independent (noncanonical) pathways [58]. A noncanonical WNT ligand, WNT5A, is highly expressed in osteoblast-lineage cells and binds to its cognate receptor, receptor tyrosine kinase-like orphan receptor 2 (ROR2), on the surface of osteoclasts [59]. Heterozygous deletion of Wnt5a or Ror 2 in mice resulted in impaired development of bone marrow-derived monocytes (BMM) to mature osteoclasts. Corresponding defects in osteoclastogenesis were also observed in mice with osteoblast-specific deletion of Wnt5a or osteoclast-specific deletion of Ror2. WNT5A enhances RANKL-induced osteoclastogenesis by upregulating RANK expression in osteoclasts via activation of the Jun-N-terminal kinase (JNK) MAPK pathway.

\subsection{WNT16}

The WNT16 locus is closely associated with bone mineral density (BMD), cortical bone thickness, and fracture risk in humans [60-62]. WNT16 is highly expressed in osteoblast-residing cortical bone, but little to no expression is detected in osteoclasts [63]. Global deletion of Wnt16 results in a specific decrease in cortical bone mass and an increase in cortical porosity, along with spontaneous fractures where there is no alteration in trabecular bone. WNT16 suppresses osteoclastogenesis in both a direct and indirect manner. In addition to direct inhibition of osteoclastogenesis via the noncanonical JNK MAPK pathway, WNT16-induced phosphorylation of JUN upregulates expression of OPG in osteoblasts, providing a direct mechanism to suppress osteoclastogenesis. Osteoblast-specific deletion of Wnt16 in mice phenocopies mice with its global deletion, suggesting osteoblasts are a primary source of WNT16, with an impact on cortical bone and skeletal integrity. Table 1 provides a list of osteoblast-derived factors that regulate osteoclasts. 
Table 1. Summary of the effect of osteoblast-derived factors on osteoclast behavior.

\begin{tabular}{|c|c|c|c|}
\hline Osteoblast-Derived Factor & Mode of Action & Influences on Osteoclasts & References \\
\hline EFNB2 & Membrane-bound & Inhibits osteoclastogenesis & [26] \\
\hline FASL & Membrane-bound & Induces osteoclast apoptosis & [36] \\
\hline SEMA3A & Membrane-bound & $\begin{array}{l}\text { Inhibits RANKL-induced } \\
\text { osteoclastogenesis }\end{array}$ & [38] \\
\hline M-CSF & Secreted & $\begin{array}{l}\text { Promotes proliferation and } \\
\text { survival of osteoclast precursor }\end{array}$ & [45] \\
\hline RANKL & $\begin{array}{l}\text { Membrane-bound and } \\
\text { secreted }\end{array}$ & $\begin{array}{l}\text { Promotes osteoclast } \\
\text { differentiation and activation }\end{array}$ & {$[6,51]$} \\
\hline OPG & Secreted & Inhibits osteoclastogenesis & {$[6,57]$} \\
\hline WNT5A & Secreted & Promotes osteoclastogenesis & [58] \\
\hline WNT16 & Secreted & Inhibits osteoclastogenesis & [63] \\
\hline
\end{tabular}

\section{Soluble Factors Released from Osteoclasts}

\subsection{Sphingosine 1 Phosphate (S1P)}

Sphingosine kinase (SPHK), expressed in osteoclasts, phosphorylates sphingosine to generate sphingosine 1 phosphate ( $\mathrm{S} 1 \mathrm{P})$ promotes osteoblastogenesis [64,65]. S1P production is enhanced in osteoclast precursors upon RANKL stimulation and S1P binds to S1P receptor on the surface of osteoblasts, resulting in increased osteoblast migration and survival. Subsequently, S1P-activated osteoblasts upregulate RANKL expression, augmenting osteoclastogenesis [66]. Further study has demonstrated that osteoclast-specific deletion of Ctsk (cathepsin K), the lysosomal cysteine protease that degrades type 1 collagen and matrix proteins during bone resorption showed enhanced bone formation by increasing S1P production from osteoclasts [65,67].

\subsection{Semaphorin $4 D(S E M A 4 D)$}

SEMA4D is an axon guidance molecule that is also expressed in osteoclasts. Osteoclast-derived SEMA4D binds to Plexin-B1 (PLXNB1) on the surface of osteoblasts, suppressing osteoblast differentiation [39]. Mice lacking Sema4d show high bone mass with increased bone forming activity and enhanced bone strength. Plxnb1-deficient mice also show similar bone phenotypes to those seen in Sema4d-deficient mice, suggesting that SEMA4D and PLXNB1 are in the same pathway. Mechanistically, binding of SEMA4D to PLXNB1 activates small GTPase RHOA and subsequently suppresses osteoblast differentiation through attenuation of insulin-like growth factor-1 (IGF-1) signaling. Administration of an anti-SEMA4D antibody prevents bone loss in a mouse model of postmenopausal osteoporosis and promotes bone formation without affecting osteoclast-mediated bone resorption, suggesting that SEMA4D is a potential therapeutic target for osteoporosis or other low bone mass disorders [68].

\subsection{Collagen Triple Helix Repeat Containing 1 (CTHRC1)}

CTHRC1 is a soluble protein released from mature osteoclasts that targets stromal cells to induce osteoblast differentiation [69]. Cthrc1 expression is upregulated when mature osteoclasts contact hydroxyapatite and calcium. Although the CTHRC1 receptor in the osteoblast has not yet been identified, recombinant CTHRC1 can induce recruitment of stromal cells and osteoblastic differentiation, promoting bone formation. In a line with this, osteoclast-specific deletion of Cthrc1 results in low bone mass with reduced bone formation. 


\subsection{Complement Component C (C3)}

Osteoclast-derived C3 is cleaved to C3a that induces osteoblastogenesis [70]. Expression of C3 is upregulated during osteoclastogenesis and a C3a receptor (C3AR) antagonist blunts the osteogenic activity of osteoclast-derived conditioned medium, while a C3AR agonist promotes osteoblast differentiation. C3 expression in bone is markedly upregulated in the setting of ovariectomy (OVX)-induced osteoporosis, or when administered with RANKL. In these settings, a C3AR antagonist attenuates bone formation activity, accelerating bone loss.

\subsection{Other Factors}

WNT10B activates the canonical WNT signaling pathway to promote osteoblast differentiation [71]. Osteocalcin promoter-driven expression of $W n t 10 b$ in osteoblasts increases bone mineral density and trabecular bone volume and number, whereas Wnt10b-deficient mice show a decrease in trabecular bone mass and serum levels of osteocalcin [71,72]. Additionally, osteoclast-derived WNT10B increases mineralization of human mesenchymal stromal cells, which suppress the presence of recombinant DKK1 (dickkopf WNT signaling pathway inhibitor 1), a WNT antagonist [65]. BMP6 in osteoclast-conditioned media induces migration and mineralization of human mesenchymal stromal cells, suggesting it as a coupling factor between osteoclasts and osteoblasts [65]. Finally, vesicular RANK has been considered as a coupling factor [73]. Vesicular RANK secreted from osteoclasts binds to osteoblastic RANKL and promotes osteoblast differentiation and bone formation by RANKL reverse signaling. RANKL is initially produced as transmembrane protein and cleaved by protease to yield a soluble form (sRANKL) and this sRANKL is required for osteoclast formation in cancellous bone as the skeleton matures [74]. Mostly, the membrane-bound form of RANKL is sufficient for osteoclast formation in developing skeleton. Accordingly, vesicular RANK might have different acting mechanism during osteoblast differentiation and bone development. Table 2 provides a list of osteoclasts-derived factors to influence on osteoblasts behavior.

Table 2. Summary of effects of osteoclast-derived factors on osteoblasts.

\begin{tabular}{cccc}
\hline Osteoclast-Derived Factor & Mode of Action & Influence on Osteoblasts & References \\
\hline EPHB4 & Membrane-bound & $\begin{array}{c}\text { Promotes osteoblastogenesis } \\
\text { and suppresses osteoblast } \\
\text { apoptosis }\end{array}$ & {$[26,30]$} \\
S1P & Secreted & $\begin{array}{c}\text { Promotes osteoblast migration } \\
\text { and survival }\end{array}$ & {$[64,65]$} \\
\hline SEMA4D & Secreted & Suppresses osteoblastogenesis & {$[39]$} \\
\hline CTHRC1 & Secreted & $\begin{array}{c}\text { Recruits stromal cells and } \\
\text { induces osteoblastogenesis }\end{array}$ & {$[69]$} \\
\hline C3 & Secreted & Promotes osteoblastogenesis & {$[70]$} \\
\hline WNT10B & Secreted & Promotes osteoblastogenesis & {$[71,72]$} \\
\hline Vesicular RANK & Secreted & Promotes osteoblastogenesis & {$[73]$} \\
\hline
\end{tabular}

\section{Matrix-Derived Coupling Factors by Bone Resorption}

\subsection{Transforming Growth Factor $\beta 1$ (TGF- $\beta 1)$}

TGF- $\beta 1$, one of the most abundant proteins in the bone matrix, contributes to bone remodeling through regulation of both osteoblasts and osteoclasts. In the bone matrix, TGF- $\beta 1$ is non-covalently bound to the latency-associated protein (LAP), keeping it in latent state by masking the receptor-binding domains of the TGF- $\beta 1[75,76]$. Accordingly, TGF- $\beta 1$ stays at an inactive state in bone matrix and is released from bone matrix in response to osteoclastic bone resorption [77]. Active TGF- $\beta 1$ recruits bone mesenchymal lineage cells to resorptive surfaces and differentiates them into bone-forming osteoblasts. 


\subsection{Insulin-Like Growth Factor Type 1 (IGF-1)}

IGF-1 is another growth factor deposited in the bone matrix, bound to insulin-like growth factor-binding protein (IGFBP) [78,79]. IGF-1 released from bone matrix is activated by acid pH during osteoclastic bone resorption [80]. Bone matrix-derived IGF-1 was found to promote osteogenesis through activation of mammalian target of rapamycin (mTOR) in osteoblast lineage cells [81]. Of note, IGF-1 concentration in the bone matrix is lower in aged rats than in young rats, suggesting a correspondence between bone volume and IGF-1 levels.

\section{Impact of Therapeutic Agents on Osteoblast-Osteoclast Interactions}

Despite there being many factors identified that regulate osteoblast-osteoclast interactions, currently very few of these pathways have resulted in approved therapeutics for the treatment of skeletal disorders. However, osteoblast-osteoclast interactions have played a powerful role in shaping the action of all currently approved drugs acting on the skeleton, including often imposing limitations on the activities of these agents. Most anti-resorptive agents inhibiting osteoclast formation and activity simultaneously suppress bone formation, whereas the activity of anabolic agents inducing bone formation are similarly tempered by simultaneously increasing bone resorption.

Denosumab is a humanized monoclonal antibody that binds RANKL and acts as an OPG-like RANK decoy receptor, disrupting the RANKL-RANK interaction and osteoclast differentiation, function, and survival, leading to a decrease in bone resorption. In patients, biannual administration of Denosumab increases bone density, and reduces the risk of vertebral, nonvertebral, and hip fractures [82]. However, as expected, inhibiting osteoclast formation by blocking RANKL-RANK signaling pathway results in reduction of osteoclast-derived coupling factors that induce osteoblast-mediated bone formation. Denosumab leads to an immediate and sustained decrease in markers of bone resorption such as urinary N-telopeptide (NTX) along with a delayed reduction in markers of bone formation, such as serum bone specific alkaline phosphatase (BSAP) [83,84].

Odanacatib, a selective cathepsin K (CTSK) inhibitor, suppresses osteoclast-mediated bone resorption $[85,86]$. CTSK is a cysteine proteinase, abundantly expressed in activated osteoclasts and secreted to extracellular space that cleaves the $\mathrm{N}$-telopeptide of collagen [87]. CTSK mutation in humans causes pycnodysostosis, a rare skeletal dysplasia, characterized by short stature, an increase in the bone density of long bones, acroosteolysis of distal phalangers and skull deformities [88]. Despite the high bone mass phenotype, patients with pycnodysostosis suffer from bone fragility with a high incidence of pathological fractures [89]. Odanacatib has received a lot of attention as a potential osteoporosis drug since it inhibits osteoclast activity and function, rather than osteoclast generation, resulting in prevention of bone resorption with more modest overall effects on the ability of osteoblasts to form bone than most other anti-resorptive agents. It still remains unclear whether these effects reflect functional blockade of osteoclast-driven coupling processes or whether CTSK inhibition may have direct effects on CTSK-expressing periosteal mesenchymal progenitors [90,91]. Although odanacatib was highly effective in reducing fractures of postmenopausal women in clinical phase-3, its further development was discontinued due to concerns regarding risk of cerebrovascular events [92].

Parathyroid hormone (PTH), a bone anabolic agent, is normally secreted by the parathyroid glands and contributes to the maintenance of calcium homeostasis through its direct actions on bone cells. Intermittent PTH administration increases bone mass by recruiting mesenchymal stromal cells into osteoblast lineage and promoting the differentiation of osteoprogenitors into mature osteoblast [93,94]. Also, PTH downregulates sclerostin (SOST) expression from osteocytes, leading to a favorable environment for osteoblast differentiation and function through enhanced WNT signaling pathway $[95,96]$. However, continuous treatment results in an increase in net bone resorption due to increases in RANKL and decreases in the RANKL decoy receptor, OPG, in osteoblasts and osteocytes [97]. As seen in each of these examples, one of the most fundamental and enduring challenges in developing increasingly effective skeletal therapeutics is overcoming the osteoblast/osteoclast interaction effects that often blunt the activity of both anti-resorptive and anabolic drugs. 


\section{Conclusions and Future Perspectives}

In this review, we provide the current knowledge of osteoblast-osteoclast communication in preserving bone homeostasis. Although multiple cells including osteocytes, chondrocytes, skeletal stem cells, endothelial cells, and immune cells play a role in controlling bone homeostasis, eventually they drive bone remodeling through the regulation of osteoblasts or osteoclasts. Accordingly, a broader understanding of the cell types regulating bone remodeling extending beyond osteoblast-osteoclast interactions will bring more insights and greater opportunities to develop therapeutics for skeletal disorders, including osteoporotic bone loss.

Traditionally, bone remodeling has been suggested as a sequential stepwise process, with initial osteoclast-mediated bone resorption followed by osteoblast-mediated bone formation [98]. However, osteoclast activity is not always restricted to specialized remodeling sites, and bone resorption is not always followed by osteoblast repopulation in the setting of pathologic skeletal disorders, such as inflammatory bone loss. Moreover, osteoclast-derived coupling can occur independent of bone resorption activity. Therefore, the spatial and temporal regulation of the bone remodeling process requires further elucidation, including further identification of the communication factors regulating osteoclast/osteoblast communication in physiologic and pathologic contexts.

Author Contributions: J.-M.K. and Z.S. wrote original draft; C.L. made the figures; M.B.G. and J.-H.S. revised and edited the manuscript. All authors have read and agreed to the published version of the manuscript.

Funding: J.-H.S. holds support from NIAMS of the NIH (R01AR068983), the AAVAA Therapeutics, and the international FOP association. MBG holds a Career Award for Medical Scientists from the Burroughs Wellcome Fund, awards from the NIH under DP5OD021351 and R01AR075585 and an award from the Pershing Square Sohn Cancer Research Alliance.

Conflicts of Interest: J.-H.S. is a scientific co-founder of AAVAA Therapeutics and holds equity in this company. Other authors declare no conflicts of interest.

$\begin{array}{ll}\text { Abbreviations } \\ \text { RUNX2 } & \text { Runt-related transcription factor 2 } \\ \text { M-CSF } & \text { Macrophage colony-stimulating factor } \\ \text { CFU-M } & \text { Macrophage colony-forming units } \\ \text { RANKL } & \text { Receptor activator of NF- } \mathrm{B} \text { (nuclear factor-kappa B) ligand } \\ \text { RANK } & \text { Receptor activator of NF- } \mathrm{B} \text { (nuclear factor-kappa B) } \\ \text { CTSK } & \text { Cathepsin K } \\ \text { MMP } & \text { Matrix metalloproteinases } \\ \text { EFNB2 } & \text { Ephrin B2 } \\ \text { FASL } & \text { Fas ligand } \\ \text { SEMA3A } & \text { Semaphorin 3A } \\ \text { NRP1 } & \text { Neuropilin-1 } \\ \text { TGF- } \beta 1 & \text { Transforming growth factor } \beta 1 \\ \text { IGF-1 } & \text { Insulin-like growth factor type 1 } \\ \text { OPG } & \text { Osteoprotegerin } \\ \text { S1P } & \text { Sphingosine 1 phosphate } \\ \text { SEMA4D } & \text { Semaphorin 4D } \\ \text { CTHRC1 } & \text { Collagen triple helix repeat containing 1 } \\ \text { C3 } & \text { Complement component c } \\ \text { PTH } & \text { Parathyroid hormone } \\ \text { SOST } & \text { Sclerostin }\end{array}$

\section{References}

1. Frost, H.M. Dynamics of bone remodeling. Bone Biodynam. 1964, 14, 315-333.

2. Feng, X.; McDonald, J.M. Disorders of bone remodeling. Annu. Rev. Pathol. 2011, 6, 121-145. [CrossRef] [PubMed] 
3. Clarke, B. Normal bone anatomy and physiology. Clin. J. Am. 2008, 3, S131-S139. [CrossRef] [PubMed]

4. Gothlin, G.; Ericsson, J.L. The osteoclast: Review of ultrastructure, origin, and structure-function relationship. Clin. Orthop. Relat. Res. 1976, 1, 201-231.

5. Feng, X.; Teitelbaum, S.L. Osteoclasts: New Insights. Bone Res. 2013, 1, 11-26. [CrossRef]

6. Boyle, W.J.; Simonet, W.S.; Lacey, D.L. Osteoclast differentiation and activation. Nature 2003, 423, $337-342$. [CrossRef]

7. Asagiri, M.; Takayanagi, H. The molecular understanding of osteoclast differentiation. Bone 2007, 40, 251-264. [CrossRef]

8. Zhu, L.; Tang, Y.; Li, X.Y.; Keller, E.T.; Yang, J.; Cho, J.S.; Feinberg, T.Y.; Weiss, S.J. Osteoclast-mediated bone resorption is controlled by a compensatory network of secreted and membrane-tethered metalloproteinases. Sci. Transl. Med. 2020, 12. [CrossRef]

9. Teitelbaum, S.L. Bone resorption by osteoclasts. Science 2000, 289, 1504-1508. [CrossRef]

10. Charles, J.F.; Aliprantis, A.O. Osteoclasts: More than 'bone eaters'. Trends Mol. Med. 2014, 20, 449-459. [CrossRef]

11. Karsenty, G.; Kronenberg, H.M.; Settembre, C. Genetic control of bone formation. Annu. Rev. Cell Dev. Biol. 2009, 25, 629-648. [CrossRef] [PubMed]

12. Long, F. Building strong bones: Molecular regulation of the osteoblast lineage. Nat. Rev. Mol. Cell Biol. 2011, 13, 27-38. [CrossRef] [PubMed]

13. Harada, S.; Rodan, G.A. Control of osteoblast function and regulation of bone mass. Nature 2003, 423, 349-355. [CrossRef] [PubMed]

14. Plotkin, L.I.; Bellido, T. Osteocytic signalling pathways as therapeutic targets for bone fragility. Nat. Rev. Endocrinol. 2016, 12, 593-605. [CrossRef] [PubMed]

15. Blair, H.C.; Larrouture, Q.C.; Li, Y.; Lin, H.; Beer-Stoltz, D.; Liu, L.; Tuan, R.S.; Robinson, L.J.; Schlesinger, P.H.; Nelson, D.J. Osteoblast Differentiation and Bone Matrix Formation In Vivo and In Vitro. Tissue Eng. Part. B Rev. 2017, 23, 268-280. [CrossRef]

16. Hattner, R.; Epker, B.N.; Frost, H.M. Suggested sequential mode of control of changes in cell behaviour in adult bone remodelling. Nature 1965, 206, 489-490. [CrossRef]

17. Langdahl, B.; Ferrari, S.; Dempster, D.W. Bone modeling and remodeling: Potential as therapeutic targets for the treatment of osteoporosis. Ther. Adv. Musculoskelet. Dis. 2016, 8, 225-235. [CrossRef]

18. Crockett, J.C.; Rogers, M.J.; Coxon, F.P.; Hocking, L.J.; Helfrich, M.H. Bone remodelling at a glance. J. Cell Sci. 2011, 124, 991-998. [CrossRef]

19. Parfitt, A.M. The coupling of bone formation to bone resorption: A critical analysis of the concept and of its relevance to the pathogenesis of osteoporosis. Metab. Bone Dis. Relat. Res. 1982, 4, 1-6. [CrossRef]

20. Khosla, S.; Oursler, M.J.; Monroe, D.G. Estrogen and the skeleton. Trends Endocrinol. Metab. 2012, $23,576-581$. [CrossRef]

21. Sobacchi, C.; Schulz, A.; Coxon, F.P.; Villa, A.; Helfrich, M.H. Osteopetrosis: Genetics, treatment and new insights into osteoclast function. Nat. Rev. Endocrinol. 2013, 9, 522-536. [CrossRef] [PubMed]

22. Mirza, F.; Canalis, E. Management of endocrine disease: Secondary osteoporosis: Pathophysiology and management. Eur. J. Endocrinol. 2015, 173, R131-R151. [CrossRef] [PubMed]

23. Andersen, T.L.; Abdelgawad, M.E.; Kristensen, H.B.; Hauge, E.M.; Rolighed, L.; Bollerslev, J.; Kjaersgaard-Andersen, P.; Delaisse, J.M. Understanding coupling between bone resorption and formation: Are reversal cells the missing link? Am. J. Pathol. 2013, 183, 235-246. [CrossRef] [PubMed]

24. Baron, R. Importance of the intermediate phases between resorption and formation in the measurement and understanding of the bone remodeling sequence. In Bone Histomorphometry; Lab Armour Montagu: Paris, France, 1977; pp. 179-183.

25. Everts, V.; Delaisse, J.M.; Korper, W.; Jansen, D.C.; Tigchelaar-Gutter, W.; Saftig, P.; Beertsen, W. The bone lining cell: Its role in cleaning Howship's lacunae and initiating bone formation. J. Bone Miner. Res. 2002, 17, 77-90. [CrossRef]

26. Zhao, C.; Irie, N.; Takada, Y.; Shimoda, K.; Miyamoto, T.; Nishiwaki, T.; Suda, T.; Matsuo, K. Bidirectional ephrinB2-EphB4 signaling controls bone homeostasis. Cell Metab. 2006, 4, 111-121. [CrossRef]

27. Tonna, S.; Poulton, I.J.; Taykar, F.; Ho, P.W.; Tonkin, B.; Crimeen-Irwin, B.; Tatarczuch, L.; McGregor, N.E.; Mackie, E.J.; Martin, T.J.; et al. Chondrocytic ephrin B2 promotes cartilage destruction by osteoclasts in endochondral ossification. Development 2016, 143, 648-657. [CrossRef] 
28. Takyar, F.M.; Tonna, S.; Ho, P.W.; Crimeen-Irwin, B.; Baker, E.K.; Martin, T.J.; Sims, N.A. EphrinB2/EphB4 inhibition in the osteoblast lineage modifies the anabolic response to parathyroid hormone. J. Bone Miner. Res. 2013, 28, 912-925. [CrossRef]

29. Kullander, K.; Klein, R. Mechanisms and functions of Eph and ephrin signalling. Nat. Rev. Mol. Cell Biol. 2002, 3, 475-486. [CrossRef]

30. Tonna, S.; Takyar, F.M.; Vrahnas, C.; Crimeen-Irwin, B.; Ho, P.W.; Poulton, I.J.; Brennan, H.J.; McGregor, N.E.; Allan, E.H.; Nguyen, H.; et al. EphrinB2 signaling in osteoblasts promotes bone mineralization by preventing apoptosis. FASEB J. 2014, 28, 4482-4496. [CrossRef]

31. Green, D.R.; Ferguson, T.A. The role of Fas ligand in immune privilege. Nat. Rev. Mol. Cell Biol. 2001, 2, 917-924. [CrossRef]

32. Wajant, H. The Fas signaling pathway: More than a paradigm. Science 2002, 296, 1635-1636. [CrossRef]

33. Sambrook, P.; Cooper, C. Osteoporosis. Lancet 2006, 367, 2010-2018. [CrossRef]

34. Kameda, T.; Mano, H.; Yuasa, T.; Mori, Y.; Miyazawa, K.; Shiokawa, M.; Nakamaru, Y.; Hiroi, E.; Hiura, K.; Kameda, A.; et al. Estrogen inhibits bone resorption by directly inducing apoptosis of the bone-resorbing osteoclasts. J. Exp. Med. 1997, 186, 489-495. [CrossRef] [PubMed]

35. Krum, S.A.; Miranda-Carboni, G.A.; Hauschka, P.V.; Carroll, J.S.; Lane, T.F.; Freedman, L.P.; Brown, M. Estrogen protects bone by inducing Fas ligand in osteoblasts to regulate osteoclast survival. EMBO J. 2008, 27, 535-545. [CrossRef] [PubMed]

36. Wang, L.; Liu, S.; Zhao, Y.; Liu, D.; Liu, Y.; Chen, C.; Karray, S.; Shi, S.; Jin, Y. Osteoblast-induced osteoclast apoptosis by fas ligand/FAS pathway is required for maintenance of bone mass. Cell Death Differ. 2015, 22, 1654-1664. [CrossRef] [PubMed]

37. Kolodkin, A.L.; Matthes, D.J.; Goodman, C.S. The semaphorin genes encode a family of transmembrane and secreted growth cone guidance molecules. Cell 1993, 75, 1389-1399. [CrossRef]

38. Hayashi, M.; Nakashima, T.; Taniguchi, M.; Kodama, T.; Kumanogoh, A.; Takayanagi, H. Osteoprotection by semaphorin 3A. Nature 2012, 485, 69-74. [CrossRef]

39. Negishi-Koga, T.; Shinohara, M.; Komatsu, N.; Bito, H.; Kodama, T.; Friedel, R.H.; Takayanagi, H. Suppression of bone formation by osteoclastic expression of semaphorin 4D. Nat. Med. 2011, 17, 1473-1480. [CrossRef]

40. Xu, R. Semaphorin 3A: A new player in bone remodeling. Cell Adh. Migr. 2014, 8, 5-10. [CrossRef]

41. Behar, O.; Golden, J.A.; Mashimo, H.; Schoen, F.J.; Fishman, M.C. Semaphorin III is needed for normal patterning and growth of nerves, bones and heart. Nature 1996, 383, 525-528. [CrossRef]

42. Fukuda, T.; Takeda, S.; Xu, R.; Ochi, H.; Sunamura, S.; Sato, T.; Shibata, S.; Yoshida, Y.; Gu, Z.; Kimura, A.; et al. Sema3A regulates bone-mass accrual through sensory innervations. Nature 2013, 497, 490-493. [CrossRef] [PubMed]

43. Fixe, P.; Praloran, V. M-CSF: Haematopoietic growth factor or inflammatory cytokine? Cytokine 1998, 10, 32-37. [CrossRef] [PubMed]

44. Stanley, E.R.; Cifone, M.; Heard, P.M.; Defendi, V. Factors regulating macrophage production and growth: Identity of colony-stimulating factor and macrophage growth factor. J. Exp. Med. 1976, 143, 631-647. [CrossRef]

45. Lacey, D.L.; Erdmann, J.M.; Shima, M.; Kling, S.; Matayoshi, A.; Ohara, J.; Perkins, S.L. Interleukin 4 enhances osteoblast macrophage colony-stimulating factor, but not interleukin 6, production. Calcif. Tissue Int. 1994, 55, 21-28. [CrossRef] [PubMed]

46. Lacey, D.L.; Timms, E.; Tan, H.L.; Kelley, M.J.; Dunstan, C.R.; Burgess, T.; Elliott, R.; Colombero, A.; Elliott, G.; Scully, S.; et al. Osteoprotegerin ligand is a cytokine that regulates osteoclast differentiation and activation. Cell 1998, 93, 165-176. [CrossRef]

47. Croft, M.; Benedict, C.A.; Ware, C.F. Clinical targeting of the TNF and TNFR superfamilies. Nat. Rev. Drug Discov. 2013, 12, 147-168. [CrossRef]

48. Kong, Y.Y.; Yoshida, H.; Sarosi, I.; Tan, H.L.; Timms, E.; Capparelli, C.; Morony, S.; Oliveira-dos-Santos, A.J.; Van, G.; Itie, A.; et al. OPGL is a key regulator of osteoclastogenesis, lymphocyte development and lymph-node organogenesis. Nature 1999, 397, 315-323. [CrossRef]

49. Yasuda, H.; Shima, N.; Nakagawa, N.; Yamaguchi, K.; Kinosaki, M.; Mochizuki, S.; Tomoyasu, A.; Yano, K.; Goto, M.; Murakami, A.; et al. Osteoclast differentiation factor is a ligand for osteoprotegerin/ osteoclastogenesis-inhibitory factor and is identical to TRANCE/RANKL. Proc. Natl. Acad. Sci. USA 1998, 95, 3597-3602. [CrossRef] 
50. Xiong, J.; Onal, M.; Jilka, R.L.; Weinstein, R.S.; Manolagas, S.C.; O’Brien, C.A. Matrix-embedded cells control osteoclast formation. Nat. Med. 2011, 17, 1235-1241. [CrossRef]

51. Li, J.; Sarosi, I.; Yan, X.Q.; Morony, S.; Capparelli, C.; Tan, H.L.; McCabe, S.; Elliott, R.; Scully, S.; Van, G.; et al. RANK is the intrinsic hematopoietic cell surface receptor that controls osteoclastogenesis and regulation of bone mass and calcium metabolism. Proc. Natl. Acad. Sci. USA 2000, 97, 1566-1571. [CrossRef]

52. Mizuno, A.; Kanno, T.; Hoshi, M.; Shibata, O.; Yano, K.; Fujise, N.; Kinosaki, M.; Yamaguchi, K.; Tsuda, E.; Murakami, A.; et al. Transgenic mice overexpressing soluble osteoclast differentiation factor (sODF) exhibit severe osteoporosis. J. Bone Miner. Metab. 2002, 20, 337-344. [CrossRef] [PubMed]

53. Simonet, W.S.; Lacey, D.L.; Dunstan, C.R.; Kelley, M.; Chang, M.S.; Luthy, R.; Nguyen, H.Q.; Wooden, S.; Bennett, L.; Boone, T.; et al. Osteoprotegerin: A novel secreted protein involved in the regulation of bone density. Cell 1997, 89, 309-319. [CrossRef]

54. Yasuda, H.; Shima, N.; Nakagawa, N.; Mochizuki, S.I.; Yano, K.; Fujise, N.; Sato, Y.; Goto, M.; Yamaguchi, K.; Kuriyama, M.; et al. Identity of osteoclastogenesis inhibitory factor (OCIF) and osteoprotegerin (OPG): A mechanism by which OPG/OCIF inhibits osteoclastogenesis in vitro. Endocrinology 1998, 139, 1329-1337. [CrossRef]

55. Li, Y.; Toraldo, G.; Li, A.; Yang, X.; Zhang, H.; Qian, W.P.; Weitzmann, M.N. B cells and T cells are critical for the preservation of bone homeostasis and attainment of peak bone mass in vivo. Blood 2007, 109, 3839-3848. [CrossRef] [PubMed]

56. Bucay, N.; Sarosi, I.; Dunstan, C.R.; Morony, S.; Tarpley, J.; Capparelli, C.; Scully, S.; Tan, H.L.; Xu, W.; Lacey, D.L.; et al. osteoprotegerin-deficient mice develop early onset osteoporosis and arterial calcification. Genes Dev. 1998, 12, 1260-1268. [CrossRef] [PubMed]

57. Theoleyre, S.; Wittrant, Y.; Tat, S.K.; Fortun, Y.; Redini, F.; Heymann, D. The molecular triad OPG/RANK/ RANKL: Involvement in the orchestration of pathophysiological bone remodeling. Cytokine Growth Factor Rev. 2004, 15, 457-475. [CrossRef]

58. Logan, C.Y.; Nusse, R. The Wnt signaling pathway in development and disease. Annu Rev. Cell Dev. Biol. 2004, 20, 781-810. [CrossRef]

59. Maeda, K.; Kobayashi, Y.; Udagawa, N.; Uehara, S.; Ishihara, A.; Mizoguchi, T.; Kikuchi, Y.; Takada, I.; Kato, S.; Kani, S.; et al. Wnt5a-Ror2 signaling between osteoblast-lineage cells and osteoclast precursors enhances osteoclastogenesis. Nat. Med. 2012, 18, 405-412. [CrossRef]

60. Medina-Gomez, C.; Kemp, J.P.; Estrada, K.; Eriksson, J.; Liu, J.; Reppe, S.; Evans, D.M.; Heppe, D.H.; Vandenput, L.; Herrera, L.; et al. Meta-analysis of genome-wide scans for total body BMD in children and adults reveals allelic heterogeneity and age-specific effects at the WNT16 locus. PLoS Genet. 2012, 8, e1002718. [CrossRef]

61. Estrada, K.; Styrkarsdottir, U.; Evangelou, E.; Hsu, Y.H.; Duncan, E.L.; Ntzani, E.E.; Oei, L.; Albagha, O.M.; Amin, N.; Kemp, J.P.; et al. Genome-wide meta-analysis identifies 56 bone mineral density loci and reveals 14 loci associated with risk of fracture. Nat. Genet. 2012, 44, 491-501. [CrossRef]

62. Koller, D.L.; Zheng, H.F.; Karasik, D.; Yerges-Armstrong, L.; Liu, C.T.; McGuigan, F.; Kemp, J.P.; Giroux, S.; Lai, D.; Edenberg, H.J.; et al. Meta-analysis of genome-wide studies identifies WNT16 and ESR1 SNPs associated with bone mineral density in premenopausal women. J. Bone Miner. Res. 2013, 28, 547-558. [CrossRef] [PubMed]

63. Moverare-Skrtic, S.; Henning, P.; Liu, X.; Nagano, K.; Saito, H.; Borjesson, A.E.; Sjogren, K.; Windahl, S.H.; Farman, H.; Kindlund, B.; et al. Osteoblast-derived WNT16 represses osteoclastogenesis and prevents cortical bone fragility fractures. Nat. Med. 2014, 20, 1279-1288. [CrossRef] [PubMed]

64. Ishii, M.; Egen, J.G.; Klauschen, F.; Meier-Schellersheim, M.; Saeki, Y.; Vacher, J.; Proia, R.L.; Germain, R.N. Sphingosine-1-phosphate mobilizes osteoclast precursors and regulates bone homeostasis. Nature 2009, 458, 524-528. [CrossRef] [PubMed]

65. Pederson, L.; Ruan, M.; Westendorf, J.J.; Khosla, S.; Oursler, M.J. Regulation of bone formation by osteoclasts involves Wnt/BMP signaling and the chemokine sphingosine-1-phosphate. Proc. Natl. Acad. Sci. USA 2008, 105, 20764-20769. [CrossRef]

66. Ryu, J.; Kim, H.J.; Chang, E.J.; Huang, H.; Banno, Y.; Kim, H.H. Sphingosine 1-phosphate as a regulator of osteoclast differentiation and osteoclast-osteoblast coupling. EMBO J. 2006, 25, 5840-5851. [CrossRef] 
67. Lotinun, S.; Kiviranta, R.; Matsubara, T.; Alzate, J.A.; Neff, L.; Luth, A.; Koskivirta, I.; Kleuser, B.; Vacher, J.; Vuorio, E.; et al. Osteoclast-specific cathepsin K deletion stimulates S1P-dependent bone formation. J. Clin. Investig. 2013, 123, 666-681. [CrossRef]

68. Cao, X. Targeting osteoclast-osteoblast communication. Nat. Med. 2011, 17, 1344-1346. [CrossRef]

69. Takeshita, S.; Fumoto, T.; Matsuoka, K.; Park, K.A.; Aburatani, H.; Kato, S.; Ito, M.; Ikeda, K. Osteoclast-secreted CTHRC1 in the coupling of bone resorption to formation. J. Clin. Investig. 2013, 123, 3914-3924. [CrossRef]

70. Matsuoka, K.; Park, K.A.; Ito, M.; Ikeda, K.; Takeshita, S. Osteoclast-derived complement component 3a stimulates osteoblast differentiation. J. Bone Miner. Res. 2014, 29, 1522-1530. [CrossRef]

71. Bennett, C.N.; Longo, K.A.; Wright, W.S.; Suva, L.J.; Lane, T.F.; Hankenson, K.D.; MacDougald, O.A. Regulation of osteoblastogenesis and bone mass by Wnt10b. Proc. Natl. Acad. Sci. USA 2005, 102, 3324-3329. [CrossRef]

72. Bennett, C.N.; Ouyang, H.; Ma, Y.L.; Zeng, Q.; Gerin, I.; Sousa, K.M.; Lane, T.F.; Krishnan, V.; Hankenson, K.D.; MacDougald, O.A. Wnt10b increases postnatal bone formation by enhancing osteoblast differentiation. J. Bone Miner. Res. 2007, 22, 1924-1932. [CrossRef] [PubMed]

73. Ikebuchi, Y.; Aoki, S.; Honma, M.; Hayashi, M.; Sugamori, Y.; Khan, M.; Kariya, Y.; Kato, G.; Tabata, Y.; Penninger, J.M.; et al. Coupling of bone resorption and formation by RANKL reverse signalling. Nature 2018, 561, 195-200. [CrossRef] [PubMed]

74. Xiong, J.; Cawley, K.; Piemontese, M.; Fujiwara, Y.; Zhao, H.; Goellner, J.J.; O’Brien, C.A. Soluble RANKL contributes to osteoclast formation in adult mice but not ovariectomy-induced bone loss. Nat. Commun. 2018, 9, 2909. [CrossRef]

75. Hinz, B. The extracellular matrix and transforming growth factor-beta1: Tale of a strained relationship. Matrix Biol. 2015, 47, 54-65. [CrossRef] [PubMed]

76. Dallas, S.L.; Park-Snyder, S.; Miyazono, K.; Twardzik, D.; Mundy, G.R.; Bonewald, L.F. Characterization and autoregulation of latent transforming growth factor beta (TGF beta) complexes in osteoblast-like cell lines. Production of a latent complex lacking the latent TGF beta-binding protein. J. Biol. Chem. 1994, 269, 6815-6821.

77. Tang, Y.; Wu, X.; Lei, W.; Pang, L.; Wan, C.; Shi, Z.; Zhao, L.; Nagy, T.R.; Peng, X.; Hu, J.; et al. TGF-beta1-induced migration of bone mesenchymal stem cells couples bone resorption with formation. Nat. Med. 2009, 15, 757-765. [CrossRef]

78. Mohan, S.; Jennings, J.C.; Linkhart, T.A.; Baylink, D.J. Primary structure of human skeletal growth factor: Homology with human insulin-like growth factor-II. Biochim. Biophys. Acta 1988, 966, 44-55. [CrossRef]

79. Bautista, C.M.; Mohan, S.; Baylink, D.J. Insulin-like growth factors I and II are present in the skeletal tissues of ten vertebrates. Metabolism 1990, 39, 96-100. [CrossRef]

80. Howard, G.A.; Bottemiller, B.L.; Turner, R.T.; Rader, J.I.; Baylink, D.J. Parathyroid hormone stimulates bone formation and resorption in organ culture: Evidence for a coupling mechanism. Proc. Natl. Acad. Sci. USA 1981, 78, 3204-3208. [CrossRef]

81. Xian, L.; Wu, X.; Pang, L.; Lou, M.; Rosen, C.J.; Qiu, T.; Crane, J.; Frassica, F.; Zhang, L.; Rodriguez, J.P.; et al. Matrix IGF-1 maintains bone mass by activation of mTOR in mesenchymal stem cells. Nat. Med. 2012, 18, 1095-1101. [CrossRef]

82. Cummings, S.R.; San Martin, J.; McClung, M.R.; Siris, E.S.; Eastell, R.; Reid, I.R.; Delmas, P.; Zoog, H.B.; Austin, M.; Wang, A.; et al. Denosumab for prevention of fractures in postmenopausal women with osteoporosis. N. Engl. J. Med. 2009, 361, 756-765. [CrossRef] [PubMed]

83. Bekker, P.J.; Holloway, D.L.; Rasmussen, A.S.; Murphy, R.; Martin, S.W.; Leese, P.T.; Holmes, G.B.; Dunstan, C.R.; DePaoli, A.M. A single-dose placebo-controlled study of AMG 162, a fully human monoclonal antibody to RANKL, in postmenopausal women. J. Bone Miner. Res. 2004, 19, 1059-1066. [CrossRef] [PubMed]

84. McClung, M.R.; Lewiecki, E.M.; Cohen, S.B.; Bolognese, M.A.; Woodson, G.C.; Moffett, A.H.; Peacock, M.; Miller, P.D.; Lederman, S.N.; Chesnut, C.H.; et al. Denosumab in postmenopausal women with low bone mineral density. N. Engl. J. Med. 2006, 354, 821-831. [CrossRef]

85. Sims, N.A.; Ng, K.W. Implications of osteoblast-osteoclast interactions in the management of osteoporosis by antiresorptive agents denosumab and odanacatib. Curr. Osteoporos. Rep. 2014, 12, 98-106. [CrossRef] [PubMed] 
86. Drake, M.T.; Clarke, B.L.; Oursler, M.J.; Khosla, S. Cathepsin K Inhibitors for Osteoporosis: Biology, Potential Clinical Utility, and Lessons Learned. Endocr. Rev. 2017, 38, 325-350. [CrossRef]

87. Costa, A.G.; Cusano, N.E.; Silva, B.C.; Cremers, S.; Bilezikian, J.P. Cathepsin K: Its skeletal actions and role as a therapeutic target in osteoporosis. Nat. Rev. Rheumatol. 2011, 7, 447-456. [CrossRef]

88. Xue, Y.; Cai, T.; Shi, S.; Wang, W.; Zhang, Y.; Mao, T.; Duan, X. Clinical and animal research findings in pycnodysostosis and gene mutations of cathepsin K from 1996 to 2011. Orphanet. J. Rare Dis. 2011, 6, 20. [CrossRef]

89. Fratzl-Zelman, N.; Valenta, A.; Roschger, P.; Nader, A.; Gelb, B.D.; Fratzl, P.; Klaushofer, K. Decreased bone turnover and deterioration of bone structure in two cases of pycnodysostosis. J. Clin. Endocrinol. Metab. 2004, 89, 1538-1547. [CrossRef]

90. Debnath, S.; Yallowitz, A.R.; McCormick, J.; Lalani, S.; Zhang, T.; Xu, R.; Li, N.; Liu, Y.; Yang, Y.S.; Eiseman, M.; et al. Discovery of a periosteal stem cell mediating intramembranous bone formation. Nature 2018, 562, 133-139. [CrossRef]

91. Recker, R.; Dempster, D.; Langdahl, B.; Giezek, H.; Clark, S.; Ellis, G.; de Villiers, T.; Valter, I.; Zerbini, C.A.; Cohn, D.; et al. Effects of Odanacatib on Bone Structure and Quality in Postmenopausal Women With Osteoporosis: 5-Year Data From the Phase 3 Long-Term Odanacatib Fracture Trial (LOFT) and its Extension. J. Bone Miner. Res. 2020, 35, 1289-1299. [CrossRef]

92. Mullard, A. Merck \&Co. drops osteoporosis drug odanacatib. Nat. Rev. Drug Discov. 2016, 15, 669. [CrossRef] [PubMed]

93. Fan, Y.; Hanai, J.I.; Le, P.T.; Bi, R.; Maridas, D.; DeMambro, V.; Figueroa, C.A.; Kir, S.; Zhou, X.; Mannstadt, M.; et al. Parathyroid Hormone Directs Bone Marrow Mesenchymal Cell Fate. Cell Metab. 2017, 25, 661-672. [CrossRef] [PubMed]

94. Ishizuya, T.; Yokose, S.; Hori, M.; Noda, T.; Suda, T.; Yoshiki, S.; Yamaguchi, A. Parathyroid hormone exerts disparate effects on osteoblast differentiation depending on exposure time in rat osteoblastic cells. J. Clin. Investig. 1997, 99, 2961-2970. [CrossRef] [PubMed]

95. Silva, B.C.; Bilezikian, J.P. Parathyroid hormone: Anabolic and catabolic actions on the skeleton. Curr. Opin. Pharmacol. 2015, 22, 41-50. [CrossRef]

96. Keller, H.; Kneissel, M. SOST is a target gene for PTH in bone. Bone 2005, 37, 148-158. [CrossRef]

97. O’Brien, C.A.; Plotkin, L.I.; Galli, C.; Goellner, J.J.; Gortazar, A.R.; Allen, M.R.; Robling, A.G.; Bouxsein, M.; Schipani, E.; Turner, C.H.; et al. Control of bone mass and remodeling by PTH receptor signaling in osteocytes. PLoS ONE. 2008, 3, e2942. [CrossRef]

98. Sims, N.A.; Martin, T.J. Osteoclasts Provide Coupling Signals to Osteoblast Lineage Cells Through Multiple Mechanisms. Annu. Rev. Physiol. 2020, 82, 507-529. [CrossRef] 